\title{
Análise do trabalho e serviço de limpeza hospitalar: contribuições da ergonomia e da psicodinâmica do trabalho
}

\author{
LAERTE IDAL SzNelwar \\ Prof. Dr. Departamento de Engenharia de Produção da POLI-USP \\ E-mail: laertesz@usp.br \\ Selma Lancman \\ Profa. Dra. Departamento de Fisioterapia, Fonoaudiologia e Terapia Ocupacional da Faculdade de Medicina-USP \\ E-mail: lancman@usp.br
}

Márcio Johlben Wu

Departamento de Engenharia de Produção da POLI-USP

Erica Alvarinho

Departamento de Fisioterapia, Fonoaudiologia e Terapia Ocupacional da Faculdade de Medicina-USP

Maria dos Santos

Departamento de Fisioterapia, Fonoaudiologia e Terapia Ocupacional da Faculdade de Medicina-USP

E-mail:mariato@usp.br

\begin{abstract}
Resumo
Neste artigo são apresentados os resultados de uma parceria envolvendo dois grupos de pesquisa que estudaram uma situação concreta de trabalho geradora de elevado índice de absenteísmo, afastamentos por doença e por acidentes de trabalho: o Serviço de Limpeza Hospitalar. O objetivo do trabalho é responder a uma demanda específica dos responsáveis por um hospital público. 0 intuito é entender a problemática referida e buscar soluções através de transformações na organização do trabalho destes profissionais. Para tanto, a equipe de pesquisa envolvida propôs que a mesma situação fosse abordada através de duas metodologias distintas: a da ergonomia e a da psicodinâmica do trabalho. O diálogo que se busca a partir da utilização dessas duas abordagens é útil para a construção de melhorias no trabalho e para analisar as relações de complementaridade, confluência e/ou divergência entre estas duas disciplinas que abordam o trabalhar sobre ópticas distintas.
\end{abstract}

Palavras-chave

Serviço de higiene; trabalho em hospitais; ergonomia; psicodinâmica do trabalho; saúde do trabalhador

\section{Work analysis in a higiene service of a hospital: contributions from ergonomics and work psychodynamics}

\begin{abstract}
This paper contains the results of a study made in partnership between two research groups. The work situation in a hygiene service of a hospital is the object of the study. The request made by the health and safety services was due to high levels of absenteeism, work diseases and accidents and the direction of the hospital was preoccupied with this scenario and would like to improve the work situation. The study was performed with two different approaches from ergonomics and from work psychodynamics. The results of the study and the dialogue between two different areas can be useful to build work improvements as well as to analyze the relationship between these two disciplines that approaches work with distinct points of view. This discussion concerns complementarities, confluence, and divergence
\end{abstract}

Key words

Hygiene services, work in hospitals, ergonomics, work psychodynamics, workers health 


\section{INTRODUĈ̣̃O}

Apesar das crescentes modificações introduzidas no trabalho e na produção nas últimas décadas, através da introdução de novas tecnologias, de mudanças na organização do trabalho, no aparecimento de novas profissões, constatase que algumas questões continuam desafiando a todos, tais como o sofrimento, as doenças, os acidentes. Estas questões, além de terem conseqüências para as próprias pessoas, acarretam prejuízos para as instituições e para a sociedade.

Com as mudanças no cenário político, econômico e produtivo, um dos setores que mais cresceu foi o de serviços nos seus mais variados tipos, que vem trazendo novos desafios no que tange à produção e ao trabalho. Contingentes crescentes de trabalhadores estão envolvidos nestas tarefas, sejam elas voltadas para o grande público, sejam elas restritas a prestar serviços dentro de uma mesma estrutura de produção.

Até recentemente o mundo do trabalho era hegemonicamente dominado por paradigmas considerados como clássicos na produção industrial, como a Organização Científica do Trabalho proposta por Taylor e seus seguidores. Parte significativa dos projetos de produção e do trabalho no setor de serviços, principalmente aquele conhecido como "serviços de massa", foi baseada na importação dos mesmos paradigmas utilizados na produção industrial clássica, tais como a fragmentação dos processos e a simplificação das tarefas. Resultados significativos foram obtidos: a racionalização de processos, a busca da homogeneidade dos serviços prestados, aumentos significativos de produtividade e o controle sobre a qualidade podem ser encontrados nas mais diversas empresas e instituições.

Todavia, ao desconsiderar as especificidades das atividades deste setor, como a complexidade da relação com o cliente e a variação constante da demanda de serviços, observamos a existência de certas incompatibilidades na realização do trabalho apesar dos resultados positivos obtidos na prestação de serviços e para as instituições. Este fato seria responsável por um aumento significativo do sofrimento e do adoecimento de trabalhadores. Doenças ligadas ao trabalho, antes afeitas basicamente ao mundo industrial e agrícola, tornaram-se parte do panorama em serviços, atingindo sobretudo trabalhadores jovens.

Esta questão paradoxal tornou-se foco de inúmeros estudos (Tonneau et al., 1996 ; Molinier, 1995), na medida em que traz um problema de alta relevância. A expansão do setor de serviços, de importância significativa na sociedade atual, estaria acontecendo em detrimento da saúde de uma parcela importante da população? Se esta hipótese estiver correta, cria-se um paradoxo: Não estaria sendo comprometido o futuro do próprio serviço, na medida em que este, de importância significativa para a qualidade de vida da popu- lação, estaria comprometendo a saúde de um contingente significativo de trabalhadores?

Um outro desafio se coloca. De que forma podem ser buscadas novas maneiras de trabalhar que, ao invés de comprometer a saúde dos trabalhadores, promovam o seu desenvolvimento enquanto profissional e ser humano? Novos compromissos deveriam ser buscados no trabalhar, através da concepção de tarefas e novas situações de trabalho que aliassem as necessidades da produção dos serviços, em termos de qualidade e produtividade, com a promoção da saúde dos trabalhadores.

Entre os setores de prestação de serviços, destacamos o de serviços de saúde em ambiente hospitalar, foco do estudo aqui proposto.

\section{A PRODUC̣ÃO DE SERVIC̣OS DE SAÚDE EM AMBIENTE HOSPITALAR}

O sistema de produção de serviços em ambiente hospitalar reveste-se de uma complexidade ímpar, principalmente quando estes serviços incluem desde atendimentos ambulatoriais até cirurgias de alta complexidade. Ao analisarmos a estrutura organizacional, os processos de produção e de trabalho, a diversidade de insumos e materiais, fica patente que os desafios para que este sistema produza serviços de qualidade e garanta a promoção da saúde de seus trabalhadores são de alta monta. Questões ligadas aos trabalhadores, à logística, à organização do trabalho, à infra-estrutura básica (utilidades, insumos...), entre outras, revelam as imensas dificuldades para que se garanta um bom funcionamento do sistema.

Aliado à questão da qualidade dos serviços e à questão da eficiência e eficácia do sistema, há desafios significativos no que concerne à saúde das pessoas que trabalham neste ambiente. Acidentes de trabalho, doenças profissionais e sinais significativos de sofrimento são resultados freqüentemente encontrados nos hospitais (Tonneau et al., 1996; Estryn-Behar et al. 1992).

Para amenizar, ou mesmo resolver, o problema dos riscos à saúde em ambiente hospitalar, é necessário aceitar o desafio de melhor compreender os processos de produção existentes e adequar o conteúdo das tarefas para que os trabalhadores envolvidos nas diferentes áreas destes locais de trabalho possam desenvolver seu trabalho de forma mais saudável.

É preciso considerar um aspecto fundamental do trabalho desenvolvido num hospital, a sua característica básica: $o$ cuidado. Esta atividade é constituída por um encontro entre uma pessoa doente, que sofre, e uma outra encarregada de lhe propiciar ajuda e conforto físico e psíquico.

O conjunto dos trabalhadores do hospital, mesmo aqueles não envolvidos diretamente com o cuidado, é obrigado a lidar com o sofrimento, a doença, a morte. O trabalho 
apresenta diferentes tipos de constrangimento: esforço físico e exigência de posturas inadequadas, equipamentos por vezes insuficientes ou mal conservados, arquitetura hospitalar que exige grandes deslocamentos, escassez de pessoal, risco de acidentes e de contágio, trabalho em turnos e noturno, ritmos de trabalho excessivos, tarefas concorrentes, etc. (Molinier, 1995; Pitta, 1990), além daqueles relacionados ao convívio com a pessoa doente.

Uma das consequiências deste estado de coisas é o número expressivo de afastamentos de trabalhadores em vários setores tanto por problemas físicos quanto decorrentes de sofrimento psíquico. Uma outra consequiência que se observa, dadas as pressões e constrangimentos organizacionais, se expressa na qualidade do atendimento prestado, que tem conseqüência imediata na melhora da saúde ou mesmo da sobrevida do cliente/paciente.

$\mathrm{O}$ desenvolvimento de conhecimento mais aprofundado sobre os hospitais e sobre o trabalho desenvolvido nestas instituições é estratégico, uma vez que as melhorias nos processos de produção poderão ter reflexos significativos em termos de qualidade de atendimento à população e, também, com relação à diminuição de custos para o sistema público de saúde. Esta economia pode ser não apenas direta, com redução de custos operacionais, mas também indireta, na medida em que poderá haver reflexos positivos para a saúde da população trabalhadora, reduzindo doenças e acidentes ligados ao trabalho.

É importante considerar que no processo de produção de serviços em hospitais há trabalhadores que têm contato direto com os pacientes e são considerados como integrantes de profissões ligadas aos cuidados à saúde e outros que não têm este contato, mas que garantem a existência do serviço através do provimento de uma série de insumos necessários à produção. Há ainda, uma outra categoria de trabalhadores, que embora tenham contato direto com os pacientes, com as famílias e com diferentes colegas, por não serem responsáveis pelo atendimento clínico, este contato é pouco ou nada relevado. É o caso dos trabalhadores da limpeza e da higiene hospitalar, que estão presentes em todos os lugares do hospital, mas que, apesar da sua atuação envolver tarefas relativamente conhecidas, desempenham uma série de outras ações, não previstas, como por exemplo ajudar direta ou indiretamente no cuidado.

\section{ERGONOMIA E A PSICODINÂMICA DO TRABALHO}

A discussão relativa à compreensão do trabalho continua sendo um grande desafio para os diversos pesquisadores. Aquilo que é realizado efetivamente por milhões de pessoas no seu dia-a-dia segue desconhecido e relegado aos bastidores da produção e, nesse sentido, as suas consequiên- cias são acessíveis somente na visibilidade dos sintomas expressos nas mentes e nos corpos dos trabalhadores. Ainda é pouco o que se conhece sobre o "trabalhar" e, sobretudo, aquilo que concerne ao que é necessário para que as tarefas sejam cumpridas a contento e para que a produção seja feita com a qualidade e a produtividade definidas pelas empresas e instituições. Ainda não são muitas as disciplinas que, ao estudarem as questões do trabalho, se preocupam com o seu conteúdo e as suas consequiências para a saúde e para a vida da população trabalhadora e para a produção. Dentre elas, destacamos a ergonomia e a psicodinâmica do trabalho. Nos últimos 50 anos, inúmeros trabalhos em ergonomia e, mais recentemente, em psicodinâmica do trabalho, têm revelado, ao meio científico e à sociedade, aspectos até então desconhecidos sobre o ato de trabalhar (Daniellou, 1996; Dejours, 1993, 1994, 1997; Wisner, 1993; Guerin et al., 2001).

Apesar da proximidade das duas disciplinas ao tratarem de aspectos ligados ao mesmo fenômeno, há diferenças significativas com relação às metodologias empregadas em função do recorte teórico/epistemológico que cada uma delas faz do objeto de estudo, o trabalhar. Em princípio, a ergonomia se volta para aspectos que se enquadram em uma perspectiva baseada na fisiologia e na psicologia cognitiva. As questões tratadas têm então como ponto de partida aquilo que pode ser explicado por estudos que privilegiam aspectos antropométricos, biomecânicos, consumo de energia, órgãos sensoriais, neurofisiologia, entre outros. Mais recentemente, com o desenvolvimento de conhecimentos oriundos da psicologia cognitiva, assim como a sua aplicação nos mais variados projetos, o campo da ergonomia tem-se transformado significativamente. Na tentativa de buscar uma síntese entre os diversos aspectos humanos com relação ao trabalhar, a ergonomia estuda o ser humano em situação de trabalho, utilizando metodologias e teorias voltadas para a compreensão da ação, do fazer. Este fato a aproxima significativamente das ciências humanas, mais especificamente da antropologia e da sociologia. Mesmo assim, como o seu objetivo é o de transformar o trabalho, adaptando-o às características humanas, ela se situa na esfera da tecnologia, fazendo parte, segundo Wisner, da arte do engenheiro. Devido ao recorte epistemológico adotado, a ergonomia não incorpora na sua abordagem questões subjetivas que dizem respeito aos sentimentos, à identidade, ao sofrimento e ao prazer, que são do âmbito do psíquico (ver Guerin et al., 2001).

Esta lacuna tem sido preenchida por estudos baseados na psicodinâmica do trabalho, linha de pesquisa e de atuação voltada mais especificamente para a questão psíquica do trabalhar. Os estudos nesta área do conhecimento têm mostrado a relevância da questão e têm colocado novos desafios para quem atua como pesquisador ou como profissional. 
Uma questão interessante surge quanto aos lugares que a ergonomia e a psicodinâmica ocupam no âmbito das áreas que estudam o trabalho. Se por um lado o ato de trabalhar é um ato síntese, onde o ser humano desenvolve suas ações por inteiro, não podendo ser separado em físico, cognitivo e psíquico, por outro, as abordagens propostas fragmentam o ato de trabalhar. A análise ergonômica não prioriza o estudo da subjetividade no trabalho, enquanto que a abordagem psicodinâmica do trabalho, ao privilegiar o sentir, não foca as condições objetivas em que ocorre o trabalho, não incorpora a questão do fazer.

Pode-se perguntar então se esta questão deve-se a incompletude característica das diferentes ciências. Se assim o fosse, bastaria juntar as duas abordagens para que fosse possível reconstruir o humano no trabalho na sua globalidade. Esta seria, a nosso ver, uma solução simplista que desconsideraria todo o debate existente entre estas duas áreas do conhecimento.

A ergonomia está voltada para a transformação efetiva das tarefas e das condições de trabalho, enquanto que a psicodinâmica do trabalho busca uma reapropriação, por parte dos trabalhadores, do sentido do trabalhar, favorecendo o seu papel como agentes de transformação do trabalho. No dizer de Molinier (2001), a ergonomia visa então desvendar o trabalho, enquanto que a psicodinâmica, o trabalhar.

A partir dessas considerações, julgamos importante fazer avançar os estudos empíricos e os conceitos que possam ajudar a compreender o trabalho em seus vários aspectos. Nesse sentido, é fundamental promover um diálogo entre os diversos campos de investigação, em especial a ergonomia e a psicodinâmica do trabalho, buscando apreender possíveis complementaridades, confluências e/ou divergências e incompatibilidades. No nosso entender, isto permitirá não só estudar situações específicas, mas também subsidiar a ampliação do campo de pesquisa teórico, que por sua vez possibilitará novas práticas e formas de ação na realidade da produção.

Além de buscar este diálogo, outro objetivo das pesquisas é também ajudar no avanço do conhecimento no setor de serviços, em especial, de uma instituição pública de prestação de atendimento à saúde. Os resultados podem ser úteis para a compreensão dos determinantes da organização do trabalho e do conteúdo das tarefas, das conseqüências para a saúde dos trabalhadores e, sobretudo, para facilitar o processo de transformações e melhorias.

\section{DESENVOLVIMENTO DO ESTUDO E RESULTADOS}

Em 2001, representantes da Comissão Interna de Prevenção e Acidentes de Trabalho de um hospital universitário, preocupados com o elevado índice de absenteísmo, adoecimentos e acidentes de trabalho dos funcionários do hospital, procuraram pesquisadores da mesma universidade ligados às áreas de engenharia de produção e terapia ocupacional. O intuito foi estabelecer parcerias que pudessem contribuir com estudos e intervenções visando à melhoria das condições de trabalho e a diminuição das problemáticas relatadas (Wu \& Alvarinho, 2002; Sznelwar et al., 2003).

Os objetivos deste projeto, de acordo com os princípios das abordagens da ergonomia e da psicodinâmica do trabalho, visavam de um lado colaborar para a melhoria das tarefas nesse hospital, considerando o seu conteúdo, a divisão do trabalho, além de outros aspectos organizacionais como os tempos, os ritmos, a relação com outros setores e com os clientes. Dessa forma, buscou-se estabelecer as relações entre a organização do trabalho, as atividades realizadas e as consequiências para a saúde do trabalhador. Buscou-se, ainda, compreender os aspectos subjetivos do trabalho, tais como: visibilidade, cooperação, reconhecimento, estratégias defensivas, processos de comunicação, entre outros.

Numa primeira etapa, as duas equipes realizaram, em conjunto, um levantamento de demanda junto ao hospital. Os principais problemas relatados pela direção, pelo serviço de medicina e segurança do trabalho e pela CIPA estavam ligados ao alto índice de absenteísmo, relacionado, na sua maior parte, a problemas de saúde. Ao mapearem estes índices para escolher dentre vários setores do hospital, foi verificado que o setor de Higiene e Desinfecção Hospitalar era um dos mais preocupantes, devido às elevadas taxas de absenteísmo, ao crescente número de adoecimentos, ao envelhecimento da população e à importância desse setor para o hospital (Felli, 1999, Torres, 1999).

Em 2001 havia 84 funcionários no setor, sendo $83 \mathrm{mu}-$ lheres, distribuídas em quatro turnos de trabalho (manhã 27 ; tarde - 17 , noite - 8 e especial - 2 ). Os demais estavam em folga, férias ou afastados. A jornada era de 6 horas, com exceção do turno da noite (regime de $12 \mathrm{~h}$ de trabalho por 36 horas de descanso). Metade deles tinha mais de 45 anos de idade - a idade variava entre 32 anos e 64 anos. Metade da população trabalhava no hospital há mais de 12 anos. $\mathrm{O}$ nível de escolaridade exigido no setor era nível fundamental (5 anos de estudo).

Com relação ao absenteísmo, houve uma redução na quantidade de afastamentos entre 1999 e 2001, de 50 para 30. Houve também uma redução da quantidade de ausências por motivos médicos, de 117 para 78. Por outro lado, os dias perdidos com afastamento médico aumentaram, de 985 para 1.170 dias. Com relação aos dias perdidos em licenças por acidente de trabalho houve um aumento significativo, de 425 para 1.145 dias. O maior número de afastamentos entre estes trabalhadores ocorreu na faixa de 40 a 49 anos entre 
aqueles que estavam trabalhando entre 6 e 10 anos no hospital. Concluiu-se que, na verdade, a diminuição dos afastamentos era devida à diminuição das licenças de curta duração, em contrapartida a um aumento de afastamentos de média e longa duração. Estes indicadores mostraram que havia uma tendência ao agravamento do quadro, principalmente porque indicavam o risco de uma redução gradativa de trabalhadores disponíveis no setor.

Em seguida, outras etapas foram desenvolvidas, tais como: conhecimento do setor, levantamento de dados sobre a produção, estudo do conteúdo das tarefas e observações livres. Para entendimento do funcionamento do setor e levantamento das tarefas e seus determinantes, foram estudados documentos relativos aos fluxos (materiais, informações, documentos), procedimentos de limpeza, escalas, insumos, critérios de qualidade, volume de produção. Esta etapa foi complementada com entrevistas com as chefias.

Após esta etapa, como parte do método proposto, as duas equipes desenvolveram trabalhos paralelos, utilizando abordagens distintas. Uma equipe deu prosseguimento à Análise Ergonômica do Trabalho (AET). A partir da elaboração de hipóteses com relação aos principais constrangimentos e inadequações da tarefa, foram realizadas observações sistemáticas e recomendações de melhorias. Para respaldar esta análise, foi proposto o envolvimento dos trabalhadores no processo. Foi então constituído um grupo, intitulado grupo de diagnóstico e melhorias, composto por trabalhadores voluntários dos três turnos de serviço (Guérin, 2001). As dinâmicas de grupo foram realizadas em paralelo às observações, fato que possibilitou um melhor entendimento do trabalho e discussões de aspectos técnicos. O grupo permitiu que os trabalhadores validassem os resultados, construíssem sugestões de melhoria, expressassem seus pontos de vista com relação à qualidade percebida, às margens de manobra, às dificuldades operacionais, às formas de comunicação e aos problemas gerados no trabalho. Além de anotações e planilhas preenchidas pelo pesquisador e pelos próprios trabalhadores, foram utilizadas fotografias e gravações em vídeo. Finalmente foram construídas sugestões de melhoria e, em seguida foi feita uma discussão onde os resultados da AET foram confrontados com os resultados do grupo de reflexão realizado sob a óptica da psicodinâmica do trabalho.

O grupo de expressão, formado por outros trabalhadores do setor, foi criado baseado nos princípios da psicodinâmica do trabalho (Dejours, 1995, 2000). A sua finalidade foi a de compreender e dar visibilidade a aspectos subjetivos ligados ao trabalhar, tais como: o conteúdo simbólico, as relações de prazer e sofrimento que os trabalhadores experimentavam com relação à sua atividade, como a organiza- ção do trabalho e as relações de poder influenciavam os processos de comunicação, a cooperação e o reconhecimento, além de identificar algumas estratégias desenvolvidas pelos trabalhadores para realizar suas tarefas. Foi proposta a criação de um espaço de discussão onde os integrantes do grupo pudessem se expressar dentro de um coletivo de pares. Para a constituição do grupo, os objetivos da ação foram apresentados aos trabalhadores de todos os turnos, dos quais 22 funcionários se dispuseram a participar como voluntários. Devido a problemas com a escala, somente dez deles puderam participar e foram escolhidos por sorteio. Ocorreram oito encontros semanais com a duração de uma hora. Ao final, foi apresentado aos trabalhadores para validação um relatório sobre os aspectos discutidos (Dejours, 1995).

\section{RESULTADOS DA ANÁLISE ERGONÔMICA}

Tipos de limpeza - Existem no hospital diversos tipos de limpeza, de acordo com o processo utilizado e o local a ser higienizado: a limpeza concorrente (limpeza diária e reposição de materiais, tais como: papel toalha e papel higiênico); a limpeza de pisos e corredores; a limpeza terminal, que envolve a limpeza de pisos, tetos, paredes e anexos (portas, vidros, janelas, luminárias etc.); a limpeza das salas cirúrgicas, que envolve também a limpeza operatória (descontaminação imediata após o derramamento de líquidos e secreções orgânicas); limpeza diária das copas; e a lavagem semanal do carro funcional. Qualquer outra intercorrência, deve ser prontamente atendida.

Critérios de Qualidade - A avaliação dos trabalhadores quanto à qualidade do trabalho realizado, feita pela chefia, envolve a limpeza do quarto, do banheiro, o abastecimento de materiais, a prontidão no atendimento, a educação e as informações prestadas quanto a problemas de manutenção. A avaliação do usuário, coletada a partir de um questionário, indicava que havia, na maioria dos casos, satisfação com relação à limpeza geral do hospital. No que tange à limpeza dos quartos, a maioria dos usuários considerava a qualidade como regular ou ruim. A limpeza dos vidros foi a que obteve as piores avaliações. A assistência prestada e a educação dos funcionários eram consideradas como de muito boa qualidade.

Tempo - O tempo para execução de uma determinada limpeza variava significativamente, segundo alguns fatores, tais como: a interferência do cliente, diferenças de arquitetura e do arranjo físico, diferença no grau de sujidade (alguns locais precisam de mais atenção em relação a outros), além de vários tipos de intercorrências. O tempo para a realização de um mesmo tipo de limpeza, como a terminal, podia variar em mais de $400 \%$. 
Estes resultados mostram a variabilidade existente com relação ao trabalho de limpeza. Este fato gerava um problema de organização que merecia um tratamento mais aprofundado, o balanceamento do trabalho e as dificuldades existentes devido a uma organização do trabalho que não privilegiava o trabalho em equipe, mas sim a repartição dos trabalhadores em diferentes áreas do hospital. Além deste aspecto, os resultados mostram que havia muito esforço físico a ser realizado, em parte relacionado com problemas da arquitetura do hospital, os tipos de mobiliário existentes (deslocamento de camas, armários, entre outros), com a inadequação das ferramentas e o descontrole com relação ao ritmo e às demandas de produção, uma vez que era impossível saber o quanto se trabalharia numa determinada jornada.

Existe um problema de balanceamento da carga entre setores e períodos do ano. Mas isto não é considerado de maneira adequada na organização do trabalho, sobrecarregando alguns trabalhadores. As limpezas terminais são parte integrante do dia-a-dia dos trabalhadores, mas não são devidamente consideradas na organização e na divisão do trabalho. Apesar do conhecimento da existência das limpezas terminais, o trabalhador nem sempre tem a possibilidade de programar adequadamente o seu tempo para realizá-las.

Os resultados das discussões desenvolvidas pelos trabalhadores no grupo de diagnóstico e melhoria estavam relacionados a estas e outras questões. A seguir será apresentado o ponto de vista destes trabalhadores, conforme a redação de relatório validado por eles:

\section{Incompatibilidade entre o real e o prescrito}

A instituição não conhece a realidade do serviço dos funcionários do setor. Existe uma tendência de simplificação da dinâmica do trabalho, procura-se adotar soluções simplistas para os problemas existentes, muitas vezes pelo fato de não conhecê-los suficientemente bem. No planejamento e gestão do setor, algumas tarefas são consideradas simples, não se leva em conta os diferentes eventos que podem afetar o trabalho. Alguns procedimentos são incompatíveis com aquilo que os trabalhadores consideram correto, há pouca explicação do motivo ou da necessidade que levou a sua adoção. Um exemplo disso está ligado ao fato de que apesar de água e sabão serem suficientes para a limpeza, em muitas situações, vários trabalhadores não confiam na sua eficácia, o que os leva a usar outros produtos, em maior quantidade, misturando-os, por acreditarem que assim atingirão melhores resultados. Há questionamentos também com relação aos procedimentos para garantir a qualidade da limpeza, por exemplo, há um certo desconforto quando limpam os banheiros e usam a mesma ferramenta para limpar a pia e o vaso sanitário. O treinamento é, em boa parte, feito pelos colegas. Portanto, certos hábitos de trabalhar são transmitidos aos mais novos, mesmo que estejam em desacordo com os procedimentos.

\section{Ausência de valorização do trabalho}

Os trabalhadores se ressentem da falta de cuidado de outros colegas e de usuários do hospital com a limpeza. Reclamam da existência de lixo descartado fora das lixeiras e do descarte de material clínico e cirúrgico de maneira inadequada. Isso é considerado por eles como desprezo pelo seu trabalho e falta de respeito à preservação do bem comum. Uma das situações que reforçam o que foi dito anteriormente é o descarte errado do "bico de papagaio" no vaso sanitário, em algumas clínicas, espalhando a urina pelo assoalho do banheiro. Também foi possível encontrar lixo em hampers do ambulatório no fim da tarde, estes deveriam conter apenas roupas, lençóis e cobertores. Além destes fatos mais diretamente ligados à limpeza propriamente dita, há uma série de atividades que eles exercem mas não são reconhecidas, pois não fazem parte do trabalho prescrito e reconhecido pela instituição. Neste caso, destacamos as informações que fornecem constantemente aos usuários do hospital e a vigilância que mantêm para evitar problemas, como por exemplo a preocupação para evitar que crianças se percam.

\section{Conhecimento da tarefa e rotatividade de setor}

Alguns trabalhadores circulam por vários setores do hospital, enquanto outros ficam fixos. Apesar de todos conhecerem os vários tipos de limpeza, existem diferenças de setor para setor, ou seja, em alguns setores algumas tarefas podem ser mais freqüentes que outras e a sua distribuição acaba sendo diferenciada nos vários setores e turnos. Estas mudanças trazem dificuldades relacionadas ao conhecimento da dinâmica de funcionamento do novo local. Além disso, a população deste setor está em processo de envelhecimento. Em breve, muitos funcionários estarão se aposentando. Ao partirem, levam consigo uma experiência acumulada durante anos de trabalho que não será compartilhada com colegas que porventura serão contratados no futuro.

\section{Os critérios de qualidade da limpeza são subjetivos}

A avaliação da qualidade do serviço realizado é diferente segundo critérios pessoais. Inicialmente a limpeza é avaliada visualmente, através da existência de partículas de lixo ou manchas de líquidos secos no chão. O olhar é o primeiro julgamento. Alguns consideram satisfatório aquilo que foi feito, enquanto outros acreditam que o serviço deva ser refeito. O julgamento ocorre entre pares, pelos chefes, por outros trabalhadores do hospital e pelos usuários. O problema é saber qual critério seguir! Ocorrem problemas quando um trabalhador considera sujo um local que acabou de ser limpo por outro colega. Isto fica acentuado nas passagens de 
plantão ou entre funcionários que trabalham em um mesmo local, pois por vezes alguns funcionários acreditam que um trabalhador está deixando trabalho para o outro com intuito de prejudicá-lo. O conflito aumenta quando a questão é delatada para a chefia que, muitas vezes, arbitra sem conhecer o que se passou.

\section{Falta de equipamentos de limpeza e precariedade da manutenção}

As enceradeiras utilizadas nas lavações são escassas, são poucas as que estão em perfeitas condições de funcionamento. Não existe uma manutenção preventiva, nem mesmo a corretiva é imediata. Alguns funcionários se apropriam das melhores enceradeiras, eles as escondem para poder utilizá-las quando precisarem. Se por um lado prejudicam os colegas, por outro não estarão sujeitos aos transtornos causados pela procura e disputa com outros para o uso da enceradeira. A falta de enceradeira pode impossibilitar a conclusão do trabalho de um funcionário naquele turno, sobrecarregando um outro colega. $\mathrm{O}$ funcionário sobrecarregado irá se desgastar mais e acusações podem começar a partir disso. Ainda, alguns preferem o uso de ferramentas mais antigas, pois acreditam que proporcionam uma melhor qualidade de limpeza. Muitas vezes, uma limpeza terminal pode ser substituída por uma limpeza mais simples devido à ausência do equipamento, que afeta a qualidade do trabalho.

\section{Integração entre colegas}

Existe pouca integração entre os funcionários. Isso está relacionado à organização do trabalho, que impõe a ele um caráter mais solitário e facilita a ocorrência de fofocas ou intrigas. O trabalho em grupo muitas vezes não é visto como sinônimo de união, mas de corpo mole. As relações de trabalho ficam enfraquecidas, deixando os funcionários pouco à vontade para falar do trabalho com os seus pares. A pouca integração dificulta ainda mais a passagem entre turnos, acentuando o processo de isolamento, levando-os a ficar mais vulneráveis frente às variações de demanda existentes ao longo dos turnos.

\section{Número reduzido de funcionários para as necessidades atuais}

O quadro atual é inferior ao existente 20 anos atrás. Com o passar dos anos, houve uma diminuição da população, devido a aposentadorias e à falta de contratação de novos trabalhadores. Além disso, há uma forte pressão sobre os trabalhadores, pois os afastamentos por motivos de doença têm sido de longa duração e não há substitutos para eles. Houve também, segundo os participantes do grupo, uma ampliação na ocupação e no número de leitos e nos atendimentos. Não houve incorporação de novas técnicas na limpe- za para compensar a falta de trabalhadores. De qualquer maneira, não há tecnologia que substitua as pessoas, pois o uso de rodo e "mop" é fundamental, devido sobretudo à flexibilidade que permitem para limpar. Os equipamentos modernos, mecanizados a automatizados, além de não terem sido adquiridos pelo hospital por limitações orçamentárias, não são adequados para todos os tipos de limpeza.

\section{$O$ projeto do hospital não facilita a limpeza}

Vários problemas foram listados pelos participantes do grupo que estão relacionados ao projeto arquitetônico do hospital. Os exemplo mais significativo foi o das janelas. Aparentemente o projeto foi elaborado sem que fossem consideradas as dificuldades para limpá-las, estas são pouco acessíveis e uma limpeza mais completa só é possível se houver uma equipe que faça a limpeza a partir da face externa do edifício. Os trabalhadores tentam alcançar os pontos mais distantes das janelas, mas as dificuldades existentes impedem que o façam, além de obrigá-los a manter posturas de trabalho desconfortáveis. Atualmente, muitas janelas estão quebradas e não podem ser reparadas pela inexistência de peças de reposição. Este problema vem sendo resolvido nas alas reformadas, onde as janelas antigas estão sendo substituídas gradativamente. Além das janelas, a ausência de ralos em certos locais dificulta o trabalho. A água é recolhida através do rodo e pano ou através do "mop" molhado. Outro aspecto que dificulta o trabalho da limpeza é a inadequação do mobiliário e o atulhamento de equipamentos em certas áreas. A mobilização do mobiliário e do equipamento para limpar adequadamente é dificultada pelo peso e pela ausência de espaço em certos setores. Além disso, a própria limpeza de equipamentos mais sensíveis exige que o trabalhador mude seu modo operatório para evitar danos ao seu funcionamento. Além do esforço exigido, as posturas para limpar são desconfortáveis e contribuem para o aparecimento de problemas osteomusculares.

\section{Variáveis fora de controle que interferem com a rotina da limpeza}

Nos grupos ainda surgiram outras questões relevantes: forte interferência do cliente no processo; carga de trabalho diferenciada ao longo do turno e do ano; esforço físico constante, dores no corpo e falta de equipamentos adequados para reduzir o esforço; problemas de projeto que dificultam o trabalho (arquitetura das janelas e mobiliário pesado); pouca valorização do "saber-fazer"; número reduzido de funcionários para as necessidades atuais; excesso de movimentação devido à falta de locais de armazenamento intermediário e pouco conhecimento sobre a toxicidade e a utilidade real dos produtos.

Dentre os principais acontecimentos que interferem na rotina estão: terminais, vômitos, secreções, "alagamentos" 
pós-banho de paciente ou outra limpeza que é pedida pela enfermagem. É possível também encontrar saboneteiras quebradas, toalheiros sem papel, bebedores com pequenos vazamentos - quando isto acontece, o funcionário pode optar por tentar resolver o problema ou emitir uma solicitação para a manutenção. Esses acontecimentos obrigam a parada do serviço e tomam um certo tempo para serem solucionados. Uma hora em média para uma limpeza terminal de quarto e cinco minutos para um vômito. As infiltrações são comuns em períodos de muita chuva. A água acaba entrando pelas janelas ou na forma de goteiras. Comentou-se que existe uma variação de demanda no transcorrer do ano. Ou seja, são comuns algumas áreas do hospital lotarem mais que outras em certos períodos do ano. Por exemplo, no inverno é muito comum os problemas respiratórios, já nos finais de semana o hospital recebe uma quantidade maior de acidentados. Tratando-se das limpezas terminais, o trabalhador sabe através das enfermeiras ou dos pacientes, o número aproximado de terminais fora de rotina para aquele dia. O grande problema é que não se pode prever o horário em que se dará a liberação do leito. A liberação está condicionada principalmente à disponibilidade de algum familiar ou conhecido em vir buscar o paciente. É comum, por exemplo, termos duas altas num dia, uma após a outra no fim do turno; caso estas mesmas altas tivessem ocorrido no começo do turno, o trabalhador não precisaria aumentar o seu ritmo para finalizar o seu serviço. No final de ano e carnaval há mais baleados, esfaqueados e bêbados; já no inverno lota o pronto atendimento da pediatria de crianças com problemas respiratórios.

\section{Forte interferência do cliente e de colegas de outros setores no processo}

O cliente participa ativamente durante a prestação do serviço. Exceto nos casos das limpezas terminais, o paciente está presente durante a limpeza e a sua interferência ocorre das maneiras as mais diversas. É muito comum que haja conversas entre o trabalhador e o paciente, este pode pedir explicações sobre um determinado procedimento de limpeza, dar palpites com relação à qualidade do serviço, questionar sobre a toxicidade de um determinado produto, reclamar dos odores, entre outros. Além disso, há uma relação que se estabelece em que o trabalhador procura apoiar a pessoa internada. Apesar de não fazer parte de seu trabalho prescrito, ele observa o paciente, mostra interesse pelo problema e busca consolá-lo. Em outras situações, procura ficar o menos possível, pois também sofre com a situação. Todo este trabalho não é reconhecido pelos colegas e quase nunca é explicitado. Há também influência dos colegas de outro setor, estes interrompem o trabalho, para pedir que algo seja limpo. A própria dinâmica do trabalho nas áreas influencia a limpeza, pois esta deve se adequar àquilo que está sendo realizado. A limpeza não pode influenciar a rotina, mas sim, ela deve ser feita na medida em que as operações avançam no setor. O ritmo e a quantidade de trabalho a ser fornecido são assim modulados. Por exemplo, o trabalhador precisa, muitas vezes, ficar em prontidão para agir, sem que possa desenvolver outra atividade.

\section{As causas para o aumento dos afastamentos por problemas osteomusculares são múltiplas}

Várias questões abordadas nas reuniões do grupo foram por eles relacionadas ao esforço físico, à fadiga e ao risco de adoecimento. Dentre estes aspectos já foram citados os problemas ligados a problemas de balanceamento da carga de trabalho, devido tanto à imprevisibilidade existente neste sistema de produção de serviços, como à própria dificuldade de dimensionar o trabalho frente às diferenças existentes entre as áreas do hospital, à inadequação dos equipamentos, aos problemas de projeto e aos mais variados eventos que podem ocorrer e que interferem no curso da ação dos trabalhadores. Um agravante para esta questão é o fato de os trabalhadores desenvolverem as suas ações isoladamente - há pouca ou quase nenhuma cooperação entre colegas prevista pela maneira como o trabalho é organizado e dividido.

Como exemplo das dificuldades existentes com relação aos móveis e aos equipamentos hospitalares com relação às ferramentas existentes para a limpeza é a utilização frequiente das pernas para mover os mais variados objetos e possibilitar a limpeza. Isto ocorre para a movimentação de equipamentos e mobílias, não é possível utilizar as mãos pois o trabalhador teria que retirar e colocar as luvas diversas vezes ao longo do dia. A movimentação é dificultada pela ausência de rodízios nos móveis e equipamentos.

Outra questão está ligada à utilização constante dos membros superiores, pois todo trabalho depende das mãos e o esforço exigido também é modulado pela qualidade e pelo tipo de equipamento. Os trabalhadores referem que o rodo, os panos e o "mop" são responsáveis por dores nos membros superiores. Por exemplo, o pano é torcido em torno de 3 a 4 vezes durante a limpeza de uma enfermaria. A força empregada na torção deve ser elevada para deixar o pano úmido e não encharcado.

Também relacionam a sua fadiga ao fato de que os produtos nem sempre estão no local e no momento em que se precisa. Os produtos de limpeza estão armazenados no armazém central. Esta política visa ao melhor controle do consumo pela chefia, mas pode causar a ausência do produto adequado, no momento certo. Muitas vezes o funcionário desperdiça tempo buscando os produtos, pois não há estoque suficiente para atender às necessidades imediatas que esteja nas proximidades. 


\section{EXEMPLOS DAS VARIAC̣̃̃ES NAS ATIVIDADES DESENVOLVIDAS}

1. Os gráficos a seguir mostram a divisão das tarefas ao longo dos turnos. A partir destes dados fica mais evidente que o trabalho é muito diferente de um turno a outro. Esta variabilidade dificulta a gestão da área e traz diferenças significativas com relação ao trabalho desenvolvido pelos trabalhadores. Ressalte-se que ainda é comum haver problemas entre as equipes, pois há tarefas que são deixadas de um turno a outro, porque há principalmente falta de tempo (vide intercorrências).

2. Os gráficos dos fluxos de atividades mostram o tempo utilizado para o desenvolvimento de diferentes ações em limpezas terminais. Cada quarto, cada situação, conforme os exemplos mostrados, difere e os motivos são os mais variados. Dentre os motivos, destacamos a quantidade de sujeira e as dificuldades com relação à limpeza das janelas.

3. Outro fator importante que interfere de maneira significativa com o curso das atividades são as chamadas fora de rotina. Neste caso, as trabalhadoras precisam interromper aquilo que estão fazendo para atender a um chamado que, no caso, deve ser respondido o mais rapidamente possível. Além da interrupção da atividade em curso, que por si só já é um transtorno, a retomada da atividade interrompida é uma dificuldade suplementar, uma vez que na maioria das vezes é necessário refazer parte da limpeza que já havia sido feita.

\section{Recomendações de melhoria}

Após a AET, foram feitas várias recomendações de melhoria, focadas em aspectos ligados a equipamentos e materiais, treinamento, organização dos horários considerando as peculiaridades dos setores, sugestão de maior flexibilidade e autonomia criando equipes de trabalho, realização de programas com outros funcionários e usuários para aumentar os cuidados com a limpeza, melhoria da qualidade do mobiliário, instalação de rodízios para reduzir o esforço e consideração das necessidades de limpeza em futuras reformas a serem realizadas no hospital. Ficou acordada com a direção do hospital a realização de uma reformulação da área onde seriam considerados os aspectos apontados neste estudo. Para tanto foi definido que seria realizado um novo projeto, baseado em metodologias derivadas da ergonomia de concepção.

\section{Distribuição das tarefas ao longo do Três Principais Turnos do servic̣o de Desinfecção Hospitalar}

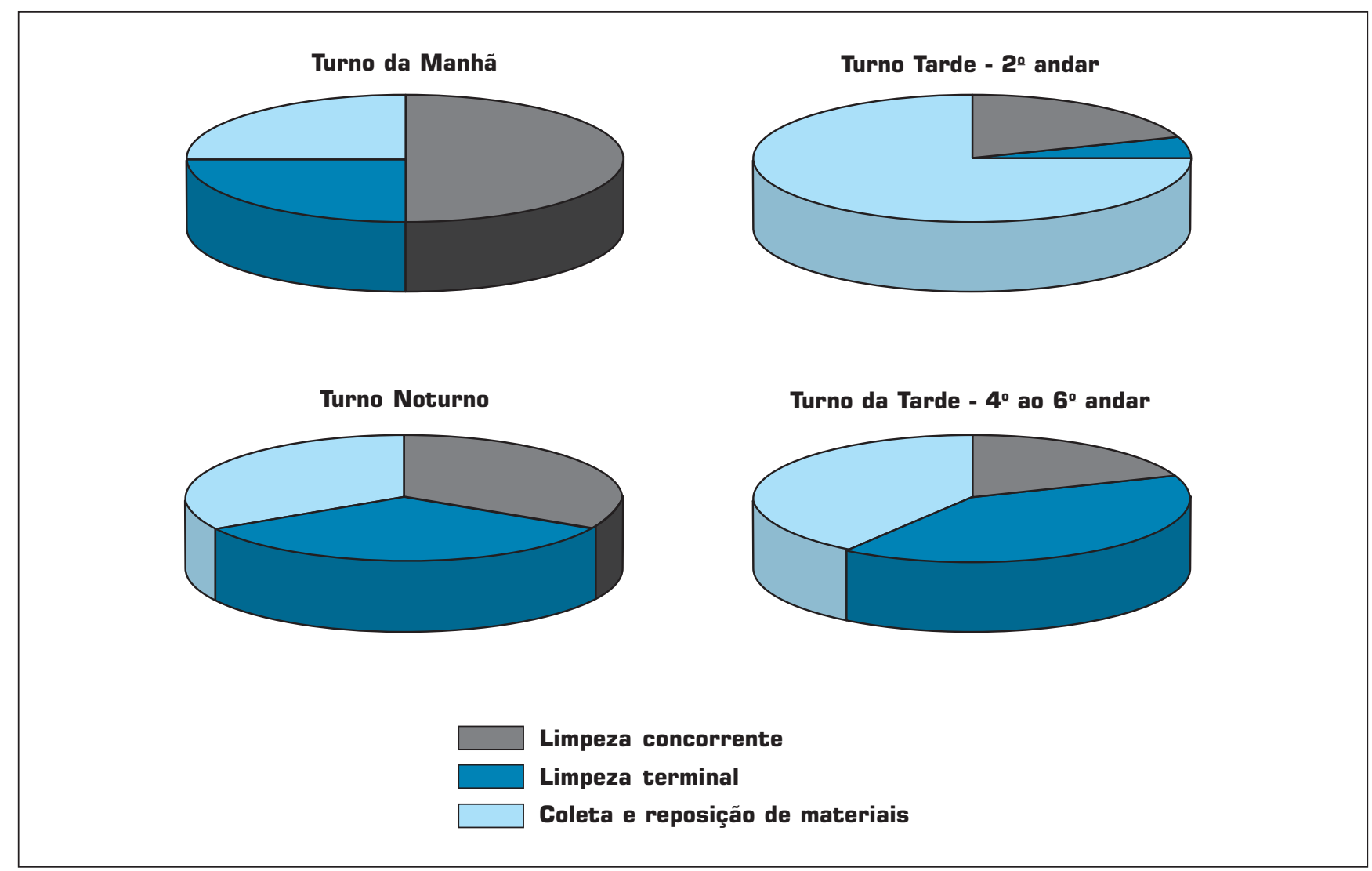




\begin{tabular}{|c|c|c|c|c|c|c|c|c|c|c|c|c|}
\hline Task Name & $15: 48$ & $15: 55$ & $16: 02$ & 16:09 & 16:16 & $16: 23$ & $16: 30$ & $16: 37$ & $16: 44$ & 16:51 & $16: 58$ & $17: 05$ \\
\hline Tirar o móvel do quarto & & \multirow{2}{*}{ 南 } & \multirow{2}{*}{ I } & \multirow{2}{*}{1} & & I & I & \multirow{2}{*}{$\begin{array}{l}\text { I } \\
\text { I }\end{array}$} & I & 1 & I & I \\
\hline Limpeza de janela & & & & & & I & I & & I & I & I & I \\
\hline Limpeza de parede & & I & $\mathbf{I}$ & I & $\nabla$ & 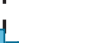 & I & i & I & i & i & i \\
\hline Limpeza ue pareue & & I & I & I & $L$ & H & I & I & I & I & I & I \\
\hline Limpeza de banheiro & & 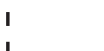 & I & I & I & & 4 & I & I & 1 & I & 1 \\
\hline Lavação e impermeabilização & & I & I & I & 1 & I & & & 1 & 1 & 1 & 1 \\
\hline
\end{tabular}

\begin{tabular}{|c|c|c|c|c|c|c|c|c|c|c|c|}
\hline Task Name & $15: 48$ & $15: 55$ & 16:02 & 16:09 & $16: 16$ & $16: 23$ & $16: 30$ & $16: 37$ & $16: 44$ & 16:51 & $16: 58$ \\
\hline Tirar o móvel do quarto & & h & I & I & I & I & I & 1 & I & I & $\mathrm{I}$ \\
\hline Limpeza de janela & & 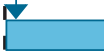 & & & & I & I & 1 & I & 1 & 1 \\
\hline Limpeza de parede & & I & I & I & 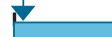 & 1 & I & i & I & I & I \\
\hline & 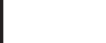 & I & I & I & 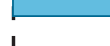 & 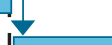 & I & I & I & 1 & 1 \\
\hline Limpeza de banheiro & t & i & I & i & i & " & & 1 & i & i & 1 \\
\hline Lavação e impermeabilização & & 1 & I & 1 & I & I & I & & & & \\
\hline
\end{tabular}

\begin{tabular}{|c|c|c|c|c|c|c|c|c|c|c|c|}
\hline Task Name & $15: 48$ & $15: 55$ & 16:02 & 16:09 & 16:16 & 16:23 & $16: 30$ & $16: 37$ & $16: 44$ & $16: 51$ & $16: 58$ \\
\hline Tirar o móvel do quarto & & h & I & I & I & I & I & I & I & I & I \\
\hline Limpeza de janela & & 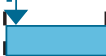 & & & & 7 & & I & 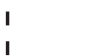 & I & I \\
\hline Limpeza de parede & & i & I & I & i & $\downarrow$ & it & 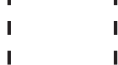 & 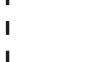 & 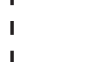 & 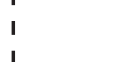 \\
\hline Limpeza de banheiro & & I & i & i & i & I & 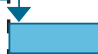 & I & 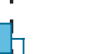 & 1 & I \\
\hline Lavação e impermeabilização & & $\begin{array}{l}1 \\
1\end{array}$ & I & $\begin{array}{l}1 \\
1\end{array}$ & I & I & 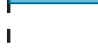 & I & & I & I \\
\hline
\end{tabular}

Número de chamadas fora de rotina

\begin{tabular}{|c|c|c|c|c|c|c|c|c|}
\hline \multirow[t]{2}{*}{ SETOR } & \multicolumn{2}{|c|}{$30 / 09 / 02$} & \multicolumn{2}{|c|}{$01 / 10 / 02$} & \multicolumn{2}{|c|}{$02 / 10 / 02$} & \multicolumn{2}{|c|}{$03 / 10 / 02$} \\
\hline & MANHÃ & TARDE & MANHÃ & TARDE & MANHÃ & TARDE & MANHÃ & TARDE \\
\hline Amb. & & & & 2 & & & & \\
\hline Berçário e Camb. & & & & & & & 1 & \\
\hline Biblioteca, Coletas, Anfiteatro & & 1 & & 1 & & & & \\
\hline Clínica Cirúrgica & & & 1 & 1 & & & 1 & 5 \\
\hline Clínica Médica & & 1 & 2 & & & 1 & 1 & \\
\hline Lab., RX & & 1 & & 1 & & & & \\
\hline Obstetrícia & & 1 & & 2 & & 1 & & 2 \\
\hline Pa.s/Pronto Socorro & & 4 & & 7 & & 5 & 4 & \\
\hline Pediatria & & & & & & 4 & 3 & \\
\hline Pessoal, Refeitório, Banheiro & & & & 2 & & & & \\
\hline UTI e Semi & & 1 & & & & & & \\
\hline UTI-Ped. & & & 1 & & & & & \\
\hline
\end{tabular}




\section{Resultados do GRUPO DE REFLEXÃO}

Várias questões relevantes foram elaboradas no grupo de reflexão. A seguir serão apresentadas e comentadas aquelas que foram consideradas mais relevantes pelo próprio grupo.

Ao longo de vários anos, foram construídas maneiras diversas de realizar as tarefas, a adoção de um estilo próprio de limpar, de acordo com o que cada um entende como "local limpo". Isto se faz em detrimento dos procedimentos prescritos e, como exemplo, pode ser mostrada a maneira de usar os produtos químicos. Alguns tendem a associar a "boa limpeza" ao cheiro exalado pelos produtos, até porque não há critérios objetivos para definir o que está ou não limpo. Alguns misturam vários produtos e água fervendo para criar uma "mistura limpa tudo" "poção mágica" e "coquetel". Acreditam que assim, garantem uma melhor limpeza.

O uso diferenciado, por vezes, até excessivo destes produtos e os possíveis agravos à saúde por risco de intoxicação pelo contato direto com a pele e/ou pela inalação não os desencoraja a mudar estes procedimentos. Relatam inclusive que aqueles que adoecem são discriminados, como nos relata uma trabalhadora: "... o funcionário que não usar hipoclorito sofre discriminação" (...) "eu tenho tóxico no sangue" (...) "eu não posso, e aí me mandaram trabalhar em escritório" (...) "eu gostava dessa mistura, aí parei quando o médico me disse que eu ia ter uma parada cardio-respiratória".

Os critérios de qualidade de avaliação que são dirigidos aos trabalhadores não são claros, o que os leva a entender esses critérios como arbitrários. Isso acaba gerando diversas situações de disputa entre trabalhadores e processos de delação, quando julgam "um trabalho malfeito".

A delação e a busca de uma aproximação e colaboração com a chefia acaba sendo uma forma de se obter pequenos privilégios, tais como organizar a escala de plantão. A falta de reconhecimento do grupo e da chefia pelo esforço em realizar um trabalho "bem feito" compromete a relação de cooperação entre eles e propicia uma perda de motivação diante da impossibilidade de verem seus esforços reconhecidos. Este reconhecimento vem, por vezes, de outros grupos, como dos pacientes internados e da equipe de enfermagem.

Referem também uma desvalorização social do seu trabalho, o que os leva a preferirem fazer parte de outras equipes a se reconhecerem como integrantes do grupo da limpeza. Por vezes, relatam fazer parte da equipe cirúrgica, da pediatria etc. É com estas outras equipes que eles tentam estabelecer um coletivo de trabalho, relações de identidade como grupo, mecanismos de cooperação e convivência.

Relatam que esta desvalorização é patente em relação aos próprios colegas da limpeza. Por exemplo, quando alguém demonstra surpresa ao vê-los lendo jornal, ou estudando, como se "fôssemos analfabetos, ignorantes". Esse tipo de preconceito é expresso ainda em comentários como: "Você está pensando que vai sair, entrou na limpeza, vai ficar na limpeza". Alguns incorporam este preconceito e sentem vergonha de seu trabalho, chegam a mentir para seus familiares e amigos sobre aquilo que fazem e se escondem quando algum conhecido chega ao hospital.

\section{“(...) Aqui no trabalho, me sinto como um patinho feio: sozinha, deslocada, sem amigos, estranha"; "(...) é difícil trabalhar cada dia com uma pessoa, falta companheirismo, conhecimento do outro... (...)". "Não há conversa entre a gente, as reclama- ções são passadas diretamente para a chefia, em tom de fofoca. Muitas vezes, são assuntos que nós mes- mos podíamos resolver."}

A falta de comunicação fica evidente na passagem de plantão, quando o funcionário do turno anterior deve comunicar para quem vai substituí-lo quaisquer intercorrências, atrasos ou falhas no serviço (áreas que ficaram sem ser limpas). É comum ocorrerem situações de emergência que impedem o funcionário de realizar o trabalho previsto, obrigando-o a limpar alguma área extra. Quem assume o posto deve compensar eventuais "lacunas" que tenham ficado do turno anterior. Quando "sobra" algum trabalho para o turno seguinte, o funcionário que assume a limpeza comunica à chefia a falha como sendo do colega e não devida a eventos que ocorreram durante o trabalho. Essas situações são comuns e estão relacionadas com intercorrências próprias de um hospital, mas a falta de comunicação faz com que os trabalhadores se sintam pessoalmente prejudicados. É importante ressaltar que a organização do trabalho não prevê horários para as passagens de plantão onde os que estão saindo do trabalho possam informar aos que chegam dos eventos e intercorrências do turno anterior.

À noite, sem a chefia presente, os trabalhadores se organizam com mais autonomia, todos são responsáveis por todos os locais. Isso termina por melhorar as relações entre eles neste turno.

Para eles, o reconhecimento mais importante pelo seu trabalho está justamente no fato de trabalharem num hospital e a importância da limpeza para o bom funcionamento deste.. “(...) se não houvesse a limpeza na sala cirúrgica não havia meios do médico entrar”; “(...) dá para sentir um certo orgulho, pois se não fosse a limpeza como seria a infecção no hospital? Acho que contribuo para a saúde". Afirmam também que trabalhar numa instituição de saúde, responsável pela cura, já lhes traz satisfação, mesmo quando sabem que aquilo que fazem na limpeza é pouco ou nada reconhecido.

Por outro lado, referem, a exemplo de outros estudos realizados com pessoal de enfermagem, um elevado nível de sofrimento, pelo convívio e confronto com o sofrimento 
dos pacientes com os quais acabam se envolvendo. Relatam que, ao longo dos anos "ficaram mais frias", e que "aprenderam a não olhar muito para o leito da UTI", mas isso não impede que saiam do serviço "com o coração apertado".

Há, também, outras funções não prescritas, imprevistas e invisíveis que os motivam durante o trabalho, tais como: ajudar crianças e pacientes perdidos a encontrarem seus parentes ou o local do atendimento, informar locais mal sinalizados, conhecer todos os problemas de manutenção do hospital. Referem também que, muitas vezes, escutam os pacientes, conversam com eles, tentam a sua maneira confortá-los. Em algumas situações são os primeiros a presenciar uma crise, acodem a pessoa e tratam de chamar socorro rapidamente. Se sentem como "parte do corpo clínico". O fato de também ajudarem o público lhes traz satisfação, pois favorece o reconhecimento daquilo que fazem, é comum receberem elogios dos usuários. Nada disso é reconhecido formalmente, inclusive porque não recebem instruções e treinamento a respeito destes assuntos.

Estes resultados mostram que a dificuldade de se constituírem como um grupo termina por dificultar também a solidariedade que diante do convívio com o sofrimento do paciente. Outros trabalhos feitos junto a trabalhadores de enfermagem mostraram como a solidariedade e a convivência são importantes mecanismos defensivos diante do sofrimento gerado pelo cuidado a enfermos (Molinier, 1995).

\section{DISCUSSÃO E CONCLUSÃO}

A utilização de duas metodologias para estudar o trabalhar de um mesmo setor, no caso o da limpeza de um hospital universitário, trouxe uma série de resultados interessantes e desafios quanto à interpretação dos resultados e à possibilidade de ação. A separação do que pode ser objetivado em um processo de análise, resultado da abordagem proposta pela Análise Ergonômica do Trabalho (AET), e questões subjetivas, reveladas por outros métodos clínicos de análise do trabalhar, como o proposto pela Psicodinâmica do Trabalho, é um recorte epistemológico que permite analisar o mesmo fenômeno sob óticas diversas. A decomposição de um ato único e singular em aspectos diferentes nos traz resultados diversos, aparentemente contraditórios. Isto fica evidente quando a AET mostra a importância de se criar grupos de limpeza, baseados em conceitos oriundos da sociotécnica (grupos semi-autônomos), e os resultados do grupo de expressão mostram a tentativa dos funcionários da limpeza de se identificarem com outras áreas do hospital onde eles estão prestando serviços (por exemplo: cirurgia, pediatria). Em parte, este fato ocorre por questões ligadas ao não-reconhecimento da importância do trabalho da limpeza e da desvalorização social da profissão. Nos parece que a necessidade de se confundir, ou mesmo de se esconder, como sendo integrante de outras equipes é uma estratégia defensiva. Por outro lado, a verificação de que o pessoal do turno da noite, sem a interferência de chefias, se organiza como equipe, torna evidente que a questão da organização do trabalho é central. Estes exemplos mostram a importância de se trabalhar simultaneamente os aspectos relevados na AET e na ação baseada na abordagem psicodinâmica para aprimorar o processo de transformação.

As escolhas que serão feitas para a concepção das mudanças dependerão de vários aspectos ligados à capacidade de investimento da instituição, dos resultados de negociações internas e ressalte-se que o envolvimento dos trabalhadores será determinante nas escolhas. Acreditamos que é importante criar condições para que se possam aumentar as possibilidades de colaboração, com o fortalecimento das equipes e das condições materiais de trabalho. Todavia é importante que seja considerado que os processos de mudança têm melhores resultados se forem respeitadas a história da instituição e a trajetória do grupo.

Estes resultados nos mostram que aplicar uma racionalidade oriunda de apenas um método de análise pode ser uma aposta fadada a um sucesso parcial, uma vez que a construção de soluções seria baseada em uma distorção, em uma escuta parcial. A desconsideração de aspectos defensivos que poderiam ser superados através de um novo desenho do conteúdo da tarefa, da organização do trabalho e do reconhecimento da profissão poderá comprometer os resultados.

Os resultados dessas duas ações, uma baseada na ergonomia e outra baseada na abordagem da psicodinâmica do trabalho, se confundem no caso aqui apresentado. Apesar de haver uma proposta inicial para tentar separar a utilização das duas disciplinas, visto que cada uma delas enfoca aspectos diferentes do trabalhar, há momentos em que esta separação fica comprometida. Explicamos este fato, pois a equipe de pesquisadores trabalhou em conjunto durante uma boa parte do processo e isto pode ter influenciado tanto o ponto de vista dos integrantes quanto o dos próprios trabalhadores envolvidos com as análises. Apesar dessa intersecção, há resultados que são claramente distintos. Por exemplo, a AET trouxe dados significativos sobre as diferenças com relação ao tempo, a interferências no trabalho, à utilização dos produtos, a sequiência de ações, entre outros. Porém, as discussões em grupo trouxeram à discussão uma série de aspectos ligados à subjetividade do trabalho. Este fato pode reforçar um dos dilemas da AET, que seria o recorte entre o que é objetivável e aspectos psíquicos que podem desestabilizar as pessoas envolvidas, interferindo inclusive no próprio andamento do trabalho. Neste caso, está em questão o próprio conceito do que seria a técnica, uma vez que o estilo no trabalhar depende do conhecimento 
técnico, mas é modulado por quem executa, detentor de uma vivência única (Clot, 1999).

No que tange ao dilema da abordagem da psicodinâmica do trabalho, espera-se que o processo de reflexão possa desencadear melhorias concretas na tarefa, mas o fato de o grupo não ter em mãos um relatório que especifique questões ligadas à tarefa e às propostas de melhoria, que serviriam para negociações futuras, pode ser uma limitação para a negociação das transformações.

Uma outra questão é o risco mostrado neste trabalho de que uma mudança que não considere o ponto de vista dos trabalhadores com relação a sua própria identificação com o trabalho possa ser um entrave, pois criaria as conhecidas "resistências às mudanças". O processo de transformação é sempre de duas vias, a transformação da organização do trabalho em um determinado setor traz uma mudança no conteúdo das tarefas e poderá desencadear um processo de melhor identificação com o trabalho. No caso em questão, o fato de haver uma maior identificação dos trabalhadores com a equipe das clínicas é, em parte, resultante de um trabalho cuja organização coloca em cheque a própria existência do coletivo, que favoreceria o que Clot (1999) chama de gênero profissional. É também um sinal claro que o pessoal de limpeza faz parte, mesmo que isto não seja reconhecido, da equipe de atenção ao paciente.

Este trabalho nos mostrou que há interesse em se utilizar de maneira complementar as duas abordagens pois, além de enriquecer os resultados, o tipo de envolvimento dos trabalhadores e da hierarquia pode facilitar as futuras transformações. Isto não significa que estamos propondo uma mistura, ou a somatória delas. É fundamental que se mantenha a diferença entre elas, pois a miscigenação das duas poderia trazer vieses conceituais e metodológicos que descaracterizariam as disciplinas e não trariam resultados significativos.

Um tipo de ação que busque trazer à tona aspectos do trabalho que, no mais das vezes, ficam restritos à intimidade dos trabalhadores, invisíveis aos outros atores da produção e também aos próprios clientes, permite talvez pela primeira vez que se reconheça o trabalhar deles. Isto pode ter consequiências positivas, pois colocará no espaço público questões relativas às dificuldades que eles encontram, sejam elas relativas à atividade executada ou ainda com relação ao sofrimento psíquico.

\section{Artigo recebido em 10/05/2004 Aprovado para publicação em 21/12/2004}

\section{- Bibliografia}

CARPENTIER-ROY, M. C. Plaisir et souffrance des infirmiéres au travail: l'emprente de l'imaginaire feminine. Revue Prevenir, Travail et Santé-mentale, n. $20,1^{\circ}$ semestre. 1990.

CLOT, Y. La fonction psychologique du travail. Le Travail Human, PUF, Paris, France, 1999.

DANIELLOU, F. L'ergonomie en quête de ses principes. Toulouse: Octarès, France, 1996.

DEJOURS, C. Comment formuler une problématique de la santé en ergonomie et en médecine du travail? Le travail Humain, tome 58 no. 1/1995:1-16
DEJOURS, C. Travail, usure mentale, nouvelle édition augmentée. De la psychopathologie à la psychodynamique du travail. Paris, Bayard Éditons, 1993.

Dejours, C., AbDouCheli, E. \& CHRISTIAN, J. Psicodinâmica do Trabalho: contribuição da Escola Dejouriana à Análise da Relação Prazer, Sofrimento e Trabalho. São Paulo: Ed. Atlas, 1994.

ESTRYN-BEHAR; M. GADBOIS, C.; POTTIER, M. Actes du colloque international "L'ergonomie à l'hôpital", Octares Editions, France, 1992.

GUERIN, F; LAVILLE, A.; DANIELLOU, F.; DURRAFFOURG, J.; KERGUELEN, A. Compreender o trabalho para transformá-lo . São Paulo: Edgard Blucher, 2001.
MOLINIER, P. Psychodynamique du Travail et identité sexuelle. Thése de doctorat en Psychologie, Conservatoire National des Arts et Metiers, 1995. Paris, França.

MOLINIER, P. Souffrance et théorie de l'action. Travailler, Revue internationale de Psychopathologie et de Psychodynamique du Travail, No 7 , 2001. França.

PITTA, A. Hospital: Dor e morte como ofício: São Paulo, Hucitec, 1990.

SZNELWAR, L. LANCMAN, S. ALVARINHO, E.; WU, M. J. Analyse du travail dans un service de nettoyage hospitalier: contributions de l'analyse ergonomique du travail et d'un groupe de réflexion inspiré de l'approche de la psychodynamique du travail. In Actes du XXXVIII ÉME CONGRĖS SELF 2003, Modeles et pratique de l'analyse du travail, 2003, p.423430. Paris.

TONNEAU, D.; BONHOURE, S.; GALLET, A.; PÉPIN, M. L'Organisation du travail dans les services de soins. Lyon, Ed. ANACT, 1996.

WISNER, A. A inteligência no trabaIho. Textos selecionados de ergonomia. FUNDACENTRO, 1993, São Paulo.

WU, M. J. \& ALVARINHO. Olhar, refletir e transformar: um aprendizado construído no Hospital Universitário/ USP, relatório final de estágio apresentado ao Hospital Universitário da USP, dezembro de 2002 . 